Nick Leach

is a principal of Partnership Consulting and has nearly 20 years' experience with leading organisations that encompass both the retail and hospitality leisure industries. He began his career with Marks and Spencer and has subsequently held senior operational and HR positions at Allied Domecq, Kingfisher and Deloitte \& Touche Consulting.

Keywords:

trends, pub leisure consumer demands
Nick Leach Highfield, 23 Warnham Road, Horsham,

West Sussex RH12 2QS, UK E-mail: nick.leach@deloitte.co.uk

\section{From coaching inn to chameleon - Trends in consumer behaviour and attitudes in the pub/bar market}

\author{
Nick Leach
}

Received (in revised form): 10th July, 2000

\begin{abstract}
The basis for this paper is a presentation the author made in January 1999 on demographic and lifestyle changes and their likely impact on the restaurant industry. Much of the data and research for that session were compiled over the previous year while the author worked on a major consulting project for Coca-Cola: 'From ingredient shopping to meal solutions - meeting the consumer appetite for change'. The project lasted over six months and investigated the potential for 'meal solutions' (or ready meals) in Europe, as traditional boundaries between the retail food market and food-service providers (not least the pub) blurred as a result of dramatic changes in people's lifestyles. It included extensive research visits across the USA and Europe, where the world's leading food retail companies were interviewed, along with customer focus groups in six countries.

As a consultant to the hospitality and leisure industry it became increasingly clear that there were a number of significant 'drivers' that were likely to have real impact on our world - irrespective of whether operating pubs, bars, restaurants or retail foodstores. The paper concentrates on these 'drivers', and the likely implications for the industry (including the pub/bar market). The opinions, while based largely on the data and consulting experience derived from relevant projects, are solely attributable to the author and are intended to provoke discussion and debate.
\end{abstract}

\section{INTRODUCTION}

With Europe moving slowly to the 'single market' and the adoption of the Euro, pubs and bars in the year 2000 and beyond will no longer just compete in one marketplace, with each other. They are now an integral part of the fast-moving, lifestyle-driven and highly customer-expectant leisure industry. The transition of the traditional brewery-based company to true leisure conglomerate has gained real momentum of late with the beers of Bass and Whitbread now being Belgian controlled - only Scottish and Newcastle and the smaller regionals are now producing on a national basis. The implications of competing in such a vast, capital-intensive and competitive market are only just dawning on 


\section{Customer needs}

\section{Market pressures}

the industry as it manoeuvres, realigns and adopts new strategies. Some fundamental questions need posing and, honestly, how often have these issues been fully explored in the past before shareholders' money was invested?

- What do our customers really want in 2000 and beyond?

- How are we assessing and responding to these needs?

- Who is (are) our market(s)?

- Who really are our competitors?

- What are our critical success factors?

- What is the risk (cost)/reward balance to deliver the success factors?

This paper will attempt to help interested parties consider such questions by reflecting on the important consumer/lifestyle trends impacting on our leisure time.

\section{MARKET SIZE AND GROWTH FORECASTS}

A market currently worth over $£ 140$ bn that is growing in real terms is clearly good news; not so reassuring is that total consumer expenditure on leisure as a percentage of total spending is predicted to fall (Figure 1). While this may or may not become reality, the influx of monies to leisure projects from new sources such as the Lottery has widened choice and, as time becomes ever more precious, the pub has to continue to compete. There are thus pressures for the pub to retain its relevance, both in a greater leisure marketplace but also where the squeeze on overall leisure 'pounds' may be tightening. As the cost of money rises, at least in the short term, and non-negotiable expenditure such as a mortgage increases, so leisure expenditure comes under greater pressure.

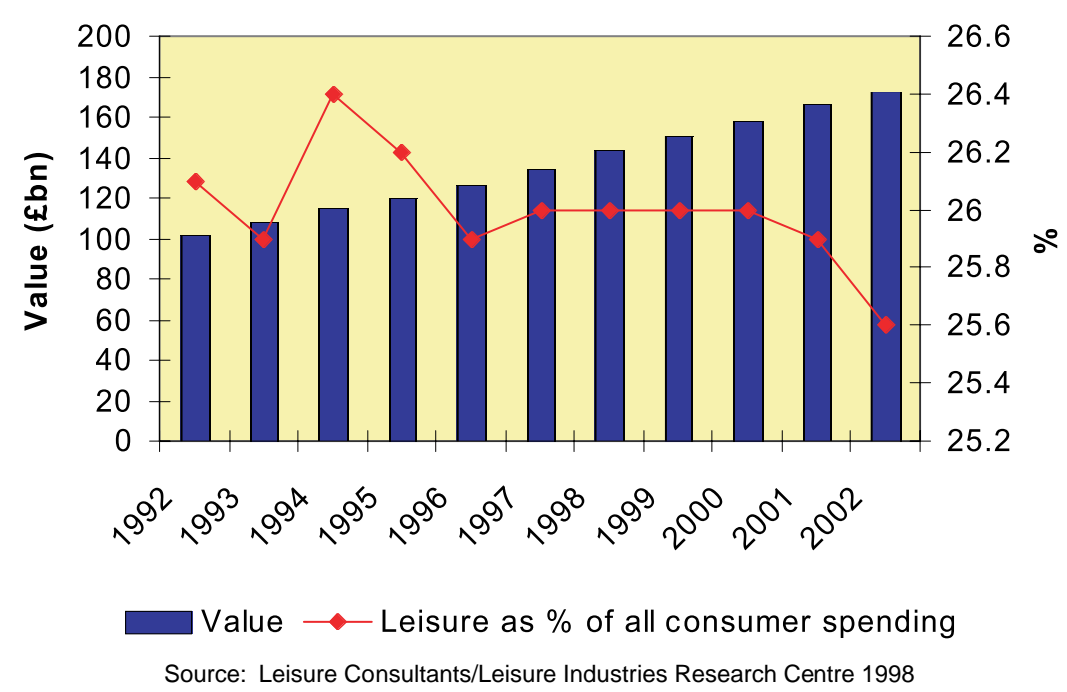

Figure 1: UK consumer expenditure on leisure, 1992-2002 


\section{A 'greying population'}

The branded approach
To understand and respond to the needs of the millennium customer is critically important - so, in general terms, who are these customers and what changes are occurring? There are, of course, many trends impacting, but the following are perhaps fundamental.

\section{AGE}

Populations across the UK and Europe are getting older and there will be a marked reduction in the number of younger people (Figure 2). A significant customer grouping for many fashion/ theme-driven offers may drop by up to 20 per cent, therefore, while the ' 50 -somethings' will grow by the same amount. These so-called 'grey panthers', affluent and now more brand and fashion conscious, have time and money to spend. The recent weaknesses of 'safe' and traditional mid-market companies such as C\&A and Marks \& Spencer is evidence of this dramatic change in consumer needs. This presents an interesting dilemma for the marketing department - how to capture this group but in a relevant and 'fashionable' way, not reminding them they're getting old. It is therefore likely that promoting the likes of the Emerald Club, Saga et al. now lacks the required sophistication.

Branding will have to become implicit through the standards and consistent quality of the offer - the millennium customer will reject the notions of 'sameness' and 'herding', and look for authenticity from which the necessary reassurances will derive.

Brands proliferated in the 1980s and 1990s largely because they instigated controls at all levels - from board room to customer interface - so that the expectation was delivered almost every time. Brands became 'pub categories', with the sophisticated marketing departments grouping by customer to create concepts such as the 'broad-based local' or the 'young persons venue' (YPV). Allied Domecq, before its demise in the pub business, probably took this

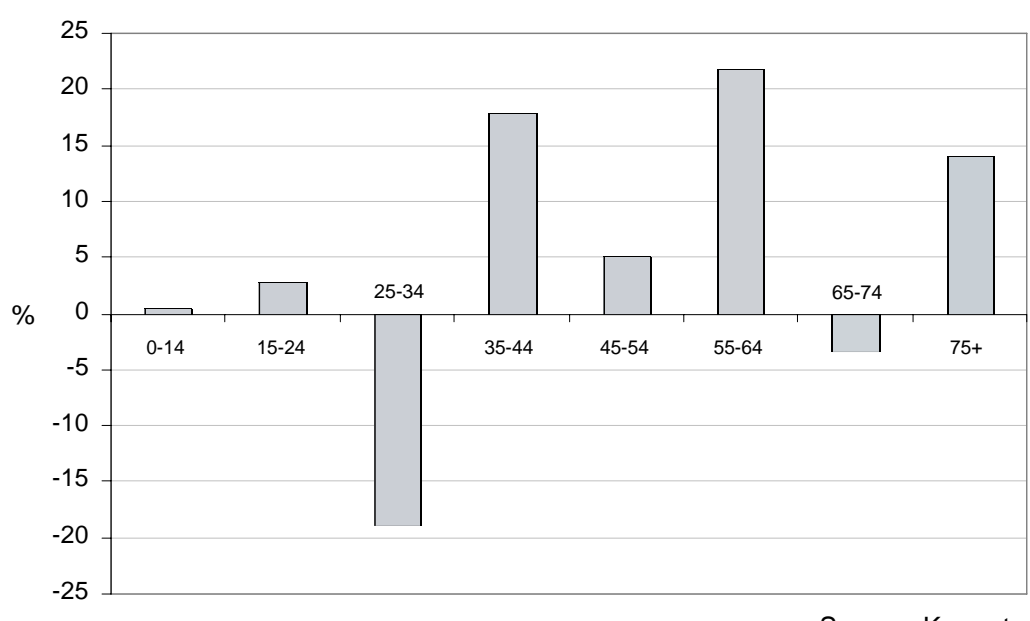

Source: Keynote 


\section{Consumer sovereignty}

\section{Fragmenting families}

trend beyond the point of no return to end up with a collection of badged outlets (Mr. Q's, Big Steak etc), lacking both the essentials of a brand and the soul and spirit of owner/operator. It is very unlikely, for example, that David Bruce would have removed the essential ingredients of a Firkin pub to the extent that they even stopped brewing on site towards the end! One can only hope that Bass show greater care.

Changes, then, are rapidly impacting, and the 'I know what I'm going to get' scenario is being largely rewritten as the 'I know what I want' scenario, albeit in generic terms of ambience, and price relative to quality and environment. (Is it only brewery executives who still smoke, or is the service charge on the air purifier still a house profit-and-loss charge and therefore a soft target to cut out?) It is the success of Vintage Inns and Chef \& Brewer that represent the new-generation pub brand - an apparent freehouse operation that delivers quality food, blackboard specials and real fires in a traditional pub setting where the 'branded' elements are largely behind the scenes. There are other good examples. Is

Wetherspoons, for example, a brand? Well maybe, but first and foremost they are good pubs with beer and food of reasonable quality at sensible prices in a comfortable (if you do not smoke you do not have to smell like an ashtray) and (more critically) neutral setting. In other words, the new consumer who 'knows what they want' can adapt the setting to suit the mood and the company. The 'Moon Under Water' is equally at home for the business lunch, the night out with friends or a drink with your partner.

\section{HOUSEHOLD STABILITY}

This is the second key driver in the consumer revolution. The implications of Figure 3 are clear. In the not too distant future, as many people will be divorcing across Europe as marrying. The purpose here is not to debate the moral questions around marriage, cohabitation and divorce, but to emphasise the fragmenting nature of the modern family unit. It is estimated that single households will double from 18 per cent of the total in 1971 to over 36 per cent

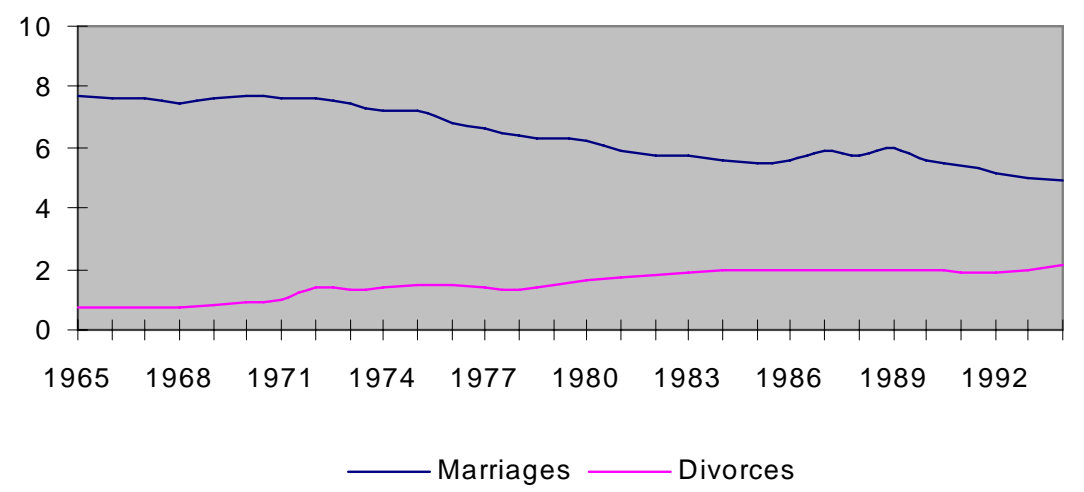

Source: Deloitte \& Touche Hospitality \& Leisure Consulting

Figure 3: Household stability - marriages and divorces per 1,000 people across 15 European countries 
New generation competitors

\section{Time pressures}

\section{Service standards}

by $2016^{1}$ — over a third of the potential market out there will live on their own and require leisure 'solutions' to meet their lifestyle needs. The pub/restaurant operator should beware, because the likes of Asda are after their business and have the vision and resources (now Wal-Mart - the world's largest retailer) to deliver. The Asda 'pub' (although planned) is probably going too far for now, but the success of offers like The Curry Pot and 'in-home' food and drink offers, at half the price of eating out, have obvious implications. This threat, combined with the 'e-business' revolution, is a formidable weapon, with in-home entertainment and home delivery probably as great a threat as the pub across the road. There are many examples of an industry revolutionised by new thinking, such as the impact on major petrol retailers and the highstreet banks when they ignored consumer trends and the power of the UK supermarket industry. Ironically, the old 'NatWest' is probably a Wetherspoons and the customer is having a c.£1.20 pint while on the mobile to First Direct or Tescobank. Ready meals, Internet pizzas and drive-thrus at supermarkets are happening, and the pub needs to remain in the 'singles' repertoire.

Does your offer add value to the customer and present absolute convenience relative to the quality and price? Consumers are increasingly cash rich/time poor, and are prepared to pay for highquality leisure experiences.

By absolute convenience the author means that time is a real driver and an important factor in the decision-making process of where and what to eat. It is often an essential element in the continual trade-off between other variables such as quality and price. For example, consumers know the ready-washed 'continental leaves' salad selection is pro rata twice the price of the whole lettuces but haven't the time or the inclination to do it themselves. They would also throw most of what was left away. A clear winwin with greater margin for the retailer and a happy customer. It would be interesting to apply the above principles to a hospitality business - is it run for the owner's convenience or with true customer focus? The modern consumer is truly time pressured and will trade up to higher-quality experiences in their precious leisure opportunities.

In large part the above issue is driven by a modern world that is changing at a frightening pace and where communication is now immediate - the world truly is a global village with cultural influences and service standards readily experienced. Two pounds for a pint of lemonade (pro rata 'splashes' - 'it's on the till like that, mate - tell the brewery'), no food after 2.01 p.m., 'what's an espresso?' and hand dryers that never work will have to go. A high percentage of the population have been to America and know it does not have to be like this any more.

The modern customer is prepared to make trade-offs - they know what is acceptable and equally, as above, what is not. The trouble is the British never tell you, unlike the Americans - they 
The new workforce

Targetting customers just never come back. To illustrate the above statement: the consumer goes to McDonalds secure in the knowledge that it is not the best burger in the world (but of relative quality to the price), yet it is delivered fast in a clean, acceptably comfortable and childfriendly (Disney-driven) environment. Why Burger King keep persisting with the 'better-tasting burger' tack to win the war is somewhat unclear.

\section{CHANGING EMPLOYMENT}

The self-employed and working-from-home industry is now worth an estimated $£ 51 \mathrm{bn}^{2}$ and, while the female workforce grows, the male workforce diminishes.

The female-driven market is, of course, vital for the future growth of the pub industry and works on a number of levels. Firstly, the growing incomes of the female workforce and their ability to spend, assisted by changing lifestyles (eg children later in life), are important. Secondly, standards are driven by the expectations of the female customer, where the conditions of the toilets and the quality of service are always at the top of their agenda. Thirdly, female-friendly offers invariably attract men in large numbers too - All Bar One is probably the best example.

Furthermore, when the independent, career female does have a family the brand standards and service criteria are likely to remain as demanding. Children too want to be treated like young adults, so future offers will need to be more than just crayons and an empty ball pit.

While clearly defining their market at given times of the trading cycle, offers will need to be exciting, flexible and adaptable if they wish to widen their appeal. However, the fundamental hygiene factors can never be compromised.

Effectively this means absolute clarity of focus as to the target audience, which may well change over the day and night trade. Are you, for example, child led (Brewers Fayre), child friendly (Beefeater) or child tolerant (Vintage Inn), and does this focus change over the trading cycle? Customers with and without children

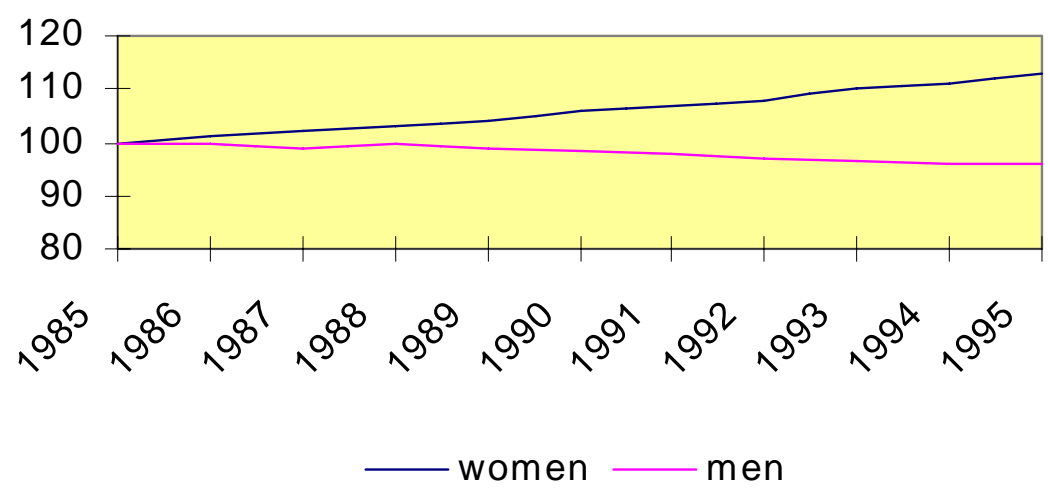

Source: Deloitte \& Touche Hospitality \& Leisure Consulting

Figure 4: Employment - activity of men and women aged 25 to 49 across 15 European countries 
Price relative to quality need to know, ideally before they are across the threshold. Perhaps the greatest contraceptive ever is a Brewers Fayre at full capacity, at $7 \mathrm{pm}$ on a wet Saturday night with three child parties on the go. To pretend to be a country pub at this time, the author suggests, is the utmost folly. Make clear the change and separate the business opportunities, as a true chameleon becomes a completely different colour with no blurring of the boundaries.

The 'falling between two stools' has never been a greater threat, as customers now demand the reassurance in advance that they, and the rest of their party, are going to have a good time. Leisure time is precious and individuals will pay to ensure that not a second of this finite commodity is wasted. So do not be afraid of charging market rates and letting people judge the quality of the product, as Pret a Manger or David Lloyd or Conran have done, for example. The modern consumer is more wary and suspicious of too cheap rather than too expensive, with the former questioned with 'what's wrong with it' and the latter 'please justify the cost through service and quality for me to truly judge the value'. Justification will have to come through the essentials, the hygiene factors such as quality, service and ambience/environment of the finished article. The selfconfident consumer is looking for the same degree of belief and professionalism in the service provider. For the property professional the true value of a licensed property no longer derives from the barrels but the wider opportunities from the location and the square metres - both in a leisure and wider use context. For example, many of the older roadside pubs in poorer areas have realised prices above their old book values and are now thriving McDonalds. Rural pubs are worth far more as food-led businesses or for the value of the land mass for housing development. As regionals consolidate, the multiples paid, as in the recent Hall \& Woodhouse acquisition of King \& Barnes, only making commercial sense for the property portfolio. It is only the closure of the brewery and disposal of valuable development land added to the economies of additional barrels that determines such a price. The industry will have to begin to measure sales per square metre, as all leading retailers have done for decades, to truly make the assets sweat.

\section{CONCLUSION}

It is hoped that the above observations provide real food for thought in looking forward at the uniquely British and essential part of our culture - the pub. The market demands ever increase, but so does the innovation and technology to respond - from Thai pubs to mealstreams to Yo Sushi conveyors and drink robots. What will forever remain essential, however, irrespective of the social and demographic changes impacting is the need for warmth and genuine hospitality. To attract the customer out you will have to offer more of an experience than they can get at home. D. H. Lawrence describes it better than anyone: 
'It was a rainy evening. The Palmerston would be the cosier ... (it's) windows were steamed over. The passage was paddled with wet feet. But the air was warm, if foul, and full of the sound of voices and the smell of beer and smoke. The men made a seat for him, and took him in warmly. He was glad ...93

Let us keep it 'cosy', but sort out the extraction (hygiene factors) and remember the growing markets of females and 50-somethings out there.

\footnotetext{
References

1. Market Assessment Publications Ltd. For Dept. of Environment/MAPS 1997.

2. First Direct Survey.

3. From 'Sons \& Lovers', D. H. Lawrence.
} 